\title{
Design of a SolidWorks-based Cultivation Bed Matrix Filler
}

\author{
GUO Yi ${ }^{1, a}$, LIU Jiwei ${ }^{2, b}$ \\ ${ }^{1}$ Department of Horticulture, Beijing Vocational College of Agriculture, Beijing, 102442, China \\ ${ }^{2}$ Department of Horticulture, Beijing Vocational College of Agriculture, Beijing, 102442, China \\ a email: guoyibvca@163.com, b email: 131900208@163.com
}

Keywords: Bed Matrix Filler, Potted Vegetable, SolidWorks, Design

\begin{abstract}
In order to meet the requirement for the automatic cultivation bed matrix filling for potted vegetables in production, a cultivation bed matrix filler, consisting of the enclosure, rotating device, filling device, compacting device and control system, is designed with SolidWorks. The result of the trial running of the sample unit made on the basis of this design shows that the filler as a whole works in a stable manner and is capable of achieving automatic matrix filling for the cultivation bed. The filler takes 30 second to complete the filling of a cultivation bed, effectively increasing work efficiency of cultivation matrix filling and reducing the labor cost; in the meantime, the filler is characterized by a simple structure, low cost of manufacturing and easy operation. The filler can be applied to provide a favorable support for enlarging production of potted vegetables, thus having a bright future of promotion in the field of vegetable potting.
\end{abstract}

\section{Introduction}

In the past few years, potted vegetables have become increasingly popular, particularly some typical leaf vegetables as purple-leaf lettuce and sedum aizoon, which are used to beautifully decorate courtyards and balconies due to their pleasant colors as well as elegant and lovely shapes and also to eliminate the pollution in the course of vegetable cultivation so as to provide people with fresh, safe and comfortable vegetables and also to beautify environment. Generally, cultivation of potted vegetables includes the following sections as preparation of cultivation matrix, sowing or transplanting, growing season handling and reaping. In order to make cultivation of potted vegetables less difficult for the city dwellers, we adopt the potted vegetable promotion pattern including preparation and filling of cultivation matrix and sowing or transplanting by farming business and later providing the potted vegetable seedlings to the city dwellers, a pattern very popular among the people.

The previous filling of cultivation matrix was completely done manually with low work efficiency and labor intensity. In case of expansion of production, the labor cost will increase clearly.

As mechanical design software based on windows platform, SolidWorks can easily and quickly create parts and compose assembly. In the meantime, it can be used to conduct interference check of assemblies and analysis of dynamic simulation so as to provide the virtual work platform to the engineering and design personnel. Thus, it has been widely applied in mechanical design. Based on SolidWorks, Xu Yonglei designed key parts of the paddy planter [1]; Guo Yi, et al. designed the conveying device of the seedling tray [2]; Xia Chunfeng designed the end actuator of grafted seedling transplantation device [3]; Wang Haixin, et al. designed loosening shovel [4]; Lu Jian, et al. designed rice seedling conveyor [5]; Tang Ningning, et al. designed a flail knife of banana stalk crushing and returning device [6]; Jiang Yanwu, et al. designed a potato sorter [7]; Zheng Donghong, et al. designed the earth sampling part of potato seeder [8]; Chu Jia, et al. designed an automatic planting device for grafted seedling with cut root [9]; and Guo Yi, et al. designed a sprout aeroponics device [10].

In order to meet the requirement for the automatic cultivation bed matrix filling for potted vegetables in production, this cultivation bed matrix filler is designed based on SolidWorks and described in this article so as to realize automatic cultivation bed matrix filling for potted vegetables 
and thus greatly save the labor cost, effectively increase work efficiency, and provide favorable support to expansion of production of potted vegetables. Characterized by a simple structure, easy operation and safety of application, the filler has a bright future in promotion in the field of vegetable potting.

\section{General Design}

The cultivation bed matrix filler consists of the enclosure, rotating device, filling device, compacting device and control system (see Fig.1). The enclosure is used to fasten varied parts. The rotating device is used to hold and take the cultivation bed to different operating spots. The filling device is used to fill cultivation matrix in the bed. The compacting device is used to compact the filling matrix inside the bed to ensure a certain degree of compactness. The control system is used to control orderly movement of varied devices to realize automation. When the cultivation bed matrix filler works, first put the cultivation bed to be filled on the loading\& unloading position of the rotating device; then the rotating platform rotates; transport the cultivation bed to the filling position and stop; the filling device fills the matrix; then the rotating platform continues to rotate to transport the cultivation bed to the compacted position and stops; the compacting device makes cultivation matrix compact; then the rotating platform continues to rotate to carry cultivation bed to the locating\& dislocating position and stops; the operating person takes off the filled cultivation bed to complete filling of a cultivation bed; when the next cultivation bed to be filled is put inside, repeat the above work to continue filling.

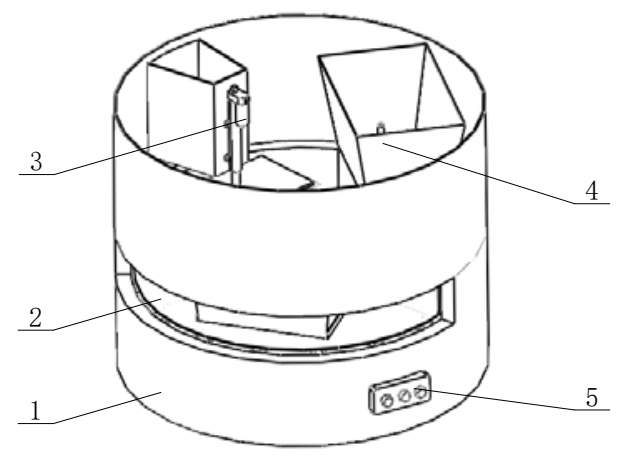

Fig.1 Overall structure

1-Enclosure 2-rotating device 3-compacting device 4-filling device 5-control system

\section{Structural Design of The Device}

Design of the Enclosure. The enclosure is used to install and fasten the parts. The enclosure is a cylindrical structure (Fig.2), with a roller in the middle for supporting the rotating platform. Inside the enclosure are installation places for the rotating device and the compacting device. The cover on the top of the enclosure can be opened to facilitate maintenance.

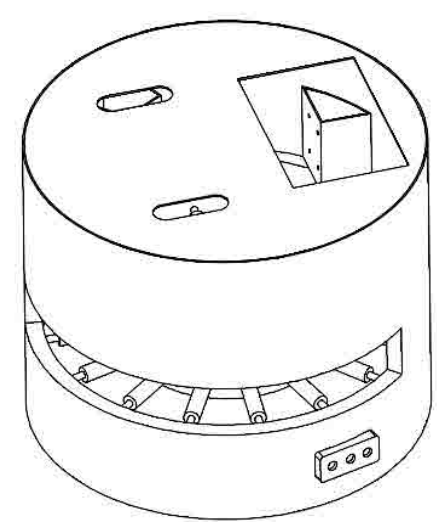

Fig.2 Enclosure 
Design of the Rotating Device. The rotating device consists of rotating platform, transmission shift and electric motor (Fig.3). The rotating platform is constructed in a cylindrical shape with stainless steel welded, consisting of top, side and base. Three holes are drilled on the top for the matrix to fall into the corresponding cultivation bed and for compaction by the compacting device; the side is used to link top to base to enable them to form a whole part, and one side has an opening; there are three cultivation positioning frames on the base to hold cultivation bed for three holes on top. Place the unfilled cultivation beds and take out the filled ones on the same side of the rotating platform. In the middle part of the rotating platform, there is a transmission shaft, which rotates with the aid of the electric motor. The rotating platform with the aid of the control system rotates in an intermittent manner. It stops after passing a working position. After taking out the filled cultivation beds and putting inside the cultivation bed to be filled, rotate through another working position after the next rotating signal is released.

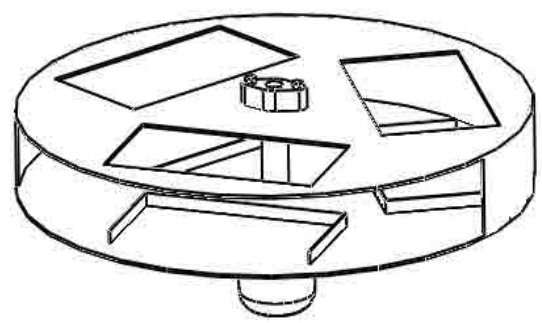

Fig.3 Rotating device

Design of Filling Device. The filling device consists of hopper, blender and electric motor (see Fig.4). The filling device is installed on one side of the upper part of the enclosure. The hopper is constructed in a shape of pyramid to hold cultivation matrix as filling. The blender is installed to the middle part of the hopper. The electric motor is used to drive the blender to rotate so as to enable cultivation matrix to fall with uniformity. During work hours, the electric motor drives the blender to rotate to enable the matrix inside the hopper to fall into corresponding positions of the rotating platform to realize filling of matrix in cultivation bed.

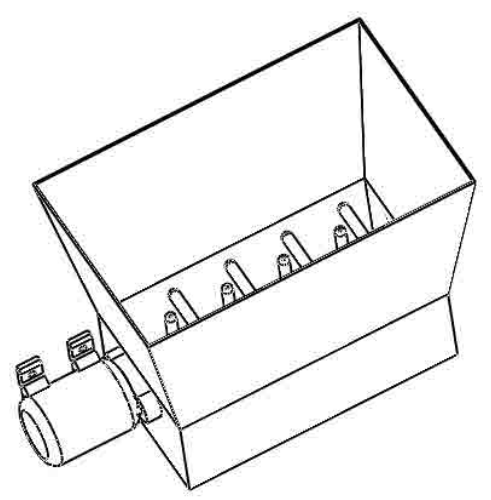

Fig.4 Filling device

Design of the Compacting Device. The compacting device consists of stamping head and linear actuator (Fig.5). The compacting device is installed on one side of the upper part of the enclosure. Size of the stamping head is determined according to the size of the cultivation bed. In operation, with aid of the control system, when the stamping head goes downward and achieves compactness of the matrix inside the cultivation bed in corresponding position on the rotating platform. 


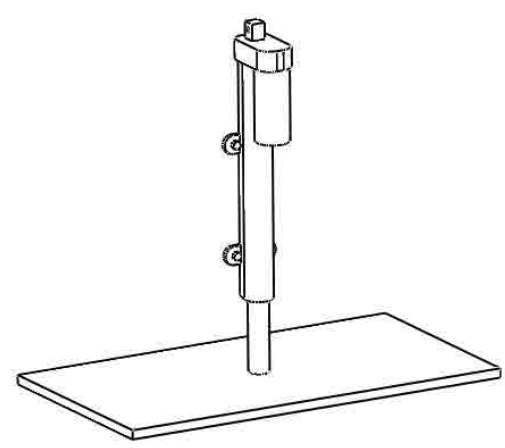

Fig.5 Compactigng device

Design of the Control System. The control system consists of master chip, relay, switch button and power adaptor. The master chip is a SCM, which controls work of all parts via program. Press the switch button once to enable the electric motors of the rotating platform and filling device and linear actuator of compacting device to work once. Then wait for the next press.

Design of the General Assembly. After completion of design of parts, by SolidWorks assembling function, assemble all parts according to assembly relation to form the assembly model of the complete unit, and analyze rationality of part design by interference check and motion simulation to form the final design result (see Fig.1).

\section{Conclusions}

The trial running of the cultivation bed matrix filler manufactured according to this design was conducted at Beijing Vocational College of Agriculture. The result of the operation shows that the device as a whole works in a stable manner and is capable of automatically filling matrix into cultivation bed. The filler takes 30 seconds to complete filling of a cultivation bed, improving efficiency of filling of cultivation matrix and reducing labor cost. The device is characterized by a simple structure, low manufacturing cost and easy operation. It achieves automatic filling of cultivation bed matrix so as to provide a favorable support for expansion of production of potted vegetables, presenting a bright future of promotion in the field of cultivation of vegetable potting.

\section{Acknowledgements}

This article is funded by the Cultivation Technology Research and Demonstration on Special Leaf Vegetables like Ice Plants Project (Project No.: XY-YF-17-01) of Technology Development and Demonstration and Promotion Fund of Beijing Vocational College of Agriculture).

\section{References}

[1] XU Yonglei, REN Wentao, HUANG Wenzhong, LV Peng, ZHANG Yuhong, ZHANG Baofeng. Design and Experimental Study on Key Components of Rice Direct Seeding Machine [J]. Journal of Shenyang Agricultural University, 2016, 47 (06): 687-694.

[2] GUO Yi, LIU Jiwei. A Seedling Tray Conveying Device And Kinematic Analysis[A]. Proceedings of 2015 International Conference on Materials Engineering and Information Technology Applications (MEITA 2015)[C]. 2015: 6.

[3] XIA Chunfeng, CAO Qixin, YANG Yang. Optimization design on end effector of grafted stock transplanting robot [J]. Journal of Chinese Agricultural Mechanization, 2016,37 (9):37-42.

[4] WANG Haixin, ZHANG Xuejun, ZHANG Chaoshu, SHI Zenglu, YAN Jinshan, JIN Wei. Based on Solidworks Film Shovel Design and Fuzzy Evaluation [J]. Journal of Agricultural Mechanization Research, 2016, 38 (11): 55-57+63. 
[5] LU Jian, LI Shifeng, LIU Rongrong. Design and experiments on the rice seedling transporter [J]. The Journal of Chinese Agricultural Mechanization, 2016,37 (9): 52-55.

[6] TANG Ningning, LI Yue, LIANG Dong, ZHANG Xirui, ZHOU Teng, SONG Yating, The Design and Optimizing on Flail Knife of Horizontal Banana Straw Crushing-returning Machine [J]. Journal of Agricultural Mechanization Research, 2017, 39 (04): 107-111+116.

[7] JIANG Yanwu, WEI Hongan, LU Xianghui, HUANG Xiaopeng, SHI Mingming. Design of potato tuber sorter[J]. Journal of Gansu Agricultural University, 2017, 52 (01): 139-143.

[8] ZHENG Donghong, CHEN Wei, DU Wenliang, LIU Guangshou, FAN Mingshou. Advanced design and experiment on soil picker device of potato planter [J]. The Journal of Chinese Agricultural Mechanization, 2016, 37 (9): 15-19.

[9] CHU Jia, ZHANG Tiezhong, LI Jun, YIN Quan, ZHANG Libo, ZHANG Wenbo. Design and Experiment of Automatic Planting Device for Root-cut Grafted Seedlings [J]. Transactions of the Chinese Society for Agricultural Machinery, 2016, 47 (10): 28-34.

[10]Guo Yi, Chen Lanfen, Suo Lang Jin ZongYang Zhen. Design of Sprout Aeroponics Equipment [A]. Proceedings of 2016 6th International Conference on Machinery, Materials, Environment, Biotechnology and Computer (MMEBC 2016) [C]. 2016: 7. 